\title{
THE EFFECTS OF DIFFERENT TYPES OF VERBAL FEEDBACK ON LEARNING A COMPLEX MOVEMENT TASK
} Verbal feedback in learning a complex movement task

\author{
JERZY SADOWSKI ${ }^{1}$, ANDRZEJ MASTALERZ2 ${ }^{2}$, TOMASZ NIŹNIKOWSKI ${ }^{3}$, \\ WALDEMAR WIŚNIOWSKI ${ }^{3}$, MICHAŁ BIEGAJŁO ${ }^{4}$, MAREK KULIK ${ }^{4}$
}

\author{
The Josef Pilsudski University of Physical Education in Warsaw, Faculty of Physical Education and \\ Sport in Biała Podlaska, Department of Athletics', Department of Biomechanics and Computer Sci- \\ ences ${ }^{2}$, Department of Gymnastics ${ }^{3}$, Department of Games and Movement Activities ${ }^{4}$
}
Mailing address: Jerzy Sadowski, Faculty of Physical Education and Sport in Biała Podlaska, 2 Akademicka Street, 21-500 Biała Podlaska, tel.: +48 83 3428758, fax: +48 83 3428800, e-mail: jerzy.sadowski@awf-bp.edu.pl

\begin{abstract}
Introduction. The aim of the study was to assess the efficiency of learning complex movement tasks with the use of different types of verbal feedback. Material and methods. Thirteen students randomly assigned to two groups (E\&P=7; P=6) took part in the study. Results. In learning a movement task verbal information on errors and correctness (E\&P) was more efficient than verbal information on correctness (P). Conclusion. At early stages too much information hinders the process of learning.
\end{abstract}

\section{Introduction}

Learning movement tasks is a complex and difficult process which has not been investigated thoroughly as yet. It particularly refers to the influence of the type and volume of feedback concerning the effects of a movement task on the efficiency and duration of learning. There has been a scarcity of data on how different types of feedback affect the efficiency of learning tasks of different technical complexity $[1,2,3]$. Some authors claim that further research is indispensable in order to determine the relations between the level of difficulty in a given movement task and the type of feedback and its degree of convergence with this task $[1,2,4,5,6,7]$.

While some researchers highlight the fact that it may be extremely difficult to determine the effects of different types of verbal, visual and verbal-visual feedback on the learning of movement tasks due to numerous complex mechanisms occurring in its process $[6,8,9,10]$, others emphasise that further research is indispensable to comprehend the process of learning entirely $[11,12,13,14,15,16]$. Williams and Hodges [17] claim that in order to understand the influence of the type of volume and accuracy on the efficiency of learning movement tasks more clearly, it is essential that a lot of issues be resolved. One of them is the amount and accuracy of feedback.

The aim of the study was to assess the efficiency of learning complex movement tasks with the use of two different verbal feedback strategies.

\section{Material and methods}

Thirteen students from the Faculty of Physical Education and Sport in Biała Podlaska randomly assigned to two groups participated in the study. The groups were as follows: group $\mathrm{E} \& \mathrm{P}=7(177 \mathrm{~cm} \pm 5.0 \mathrm{~cm}, 81.2 \mathrm{~kg} \pm 3.8 \mathrm{~kg}, 20.3 \pm 1.1$ years $)$, group $\mathrm{P}=6(178 \mathrm{~cm} \pm 4.0 \mathrm{~cm}, 79.4 \mathrm{~kg} \pm 3.6 \mathrm{~kg}, 20.4 \pm 1.2$ years $)$.

A 6-week experiment was carried out. Training sessions took place three times a week (on Mondays, Wednesdays and Fridays). In total, each subject participated in 18 workouts. Each session lasted for 60 minutes. In the course of the examinations the subjects learnt to perform a vertical jump with swinging arms forward and upward, pulling the knees to the chest and grabbing the shanks followed by half-squat landing with arms sideward. The subjects had not been familiar with this task before.

Progressive-parts method was utilised, i.e. the task was divided into parts. The subjects mastered the preparatory phase during training sessions 1-4; sessions 5-8 were devoted to acquiring the main phase, while sessions 9-12 involved learning to perform the final phase. Workouts $13-16$ were devoted to acquiring the whole movement task.

Every training session involved performing 20 task repetitions in sets of 5 repetitions each. After each set the subjects received feedback (knowledge of results). Group E\&P obtained information on errors and on how to correct them. Group P received feedback on the correctness of performance only. A pretest was conducted two days before commencing the experiment, while a posttest was carried out one day after finishing it. A retention test was performed seven days after the experiment. In the tests, following a standard warm-up, the subjects were asked to perform a single movement task in question. Three gymnastic judges rated their performance on a scale of 1 to 10 according to FIG. For each minor error they deducted 0-0.3 pts, for a medium one - 0.4-0.6 pts, while for a major error they deducted 0.7-1 pts from a maximal score of $10 \mathrm{pts}$.

\section{Methods of statistic analysis}

The ANOVA was used to estimate statistical significance of differences in measurements. The normality of distribution and homogeneity of variances were tested with the Shapiro-Wilk test. After the verification of the prerequisite, studied variables were analysed by means of two-way mixed-factor analysis of variance, Group (2) x Test Time (3), with the two experimental groups representing a between-subjects factor and the testing times representing a within-subjects factor. Statistical significance was accepted at $\mathrm{p}<.05$. For significant differences, Fisher post hoc test was used. The results were statistically analysed with the use of 
the Statistica programme (StatSoft, Inc. 2005, STATISTICA, version 7.1. www.statsoft.com).

\section{Results}

The ANOVA with repeated measures analysis revealed a significant effect of Test Time $(F(2,22)=6.12 ; p=.007)$. There were no effects of Group $(F(1,11)=0.99 ; p=.340)$ as well as Group $\mathrm{x}$ Test Time interaction $(\mathrm{F}(2,22)=0.62, \mathrm{p}=.545)$. Means and standard deviations are displayed in Figure 1.

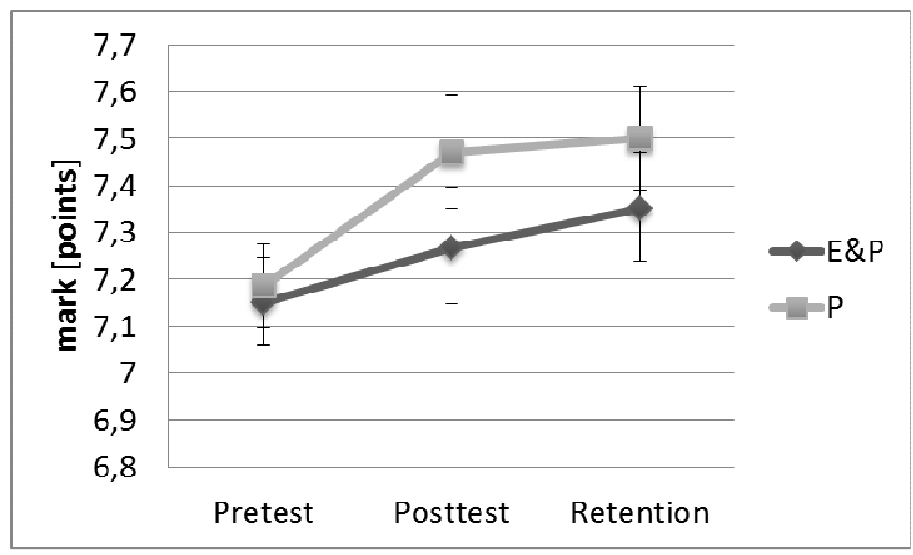

Figure 1. Means and standard deviations of experts' marks across test times (pretest, acquisition and posttest) in the group with verbal information on errors and correctness (E\&P) and in the group with verbal information on correctness (P)

The relative increases in judges' ratings are displayed in Figure 2. Fisher post hoc tests $(\mathrm{p}<0.05)$ were conducted to identify where the differences lie. Post hoc comparison indicated that a significant improvement of performance was observed only in the group with verbal information on correctness (P).

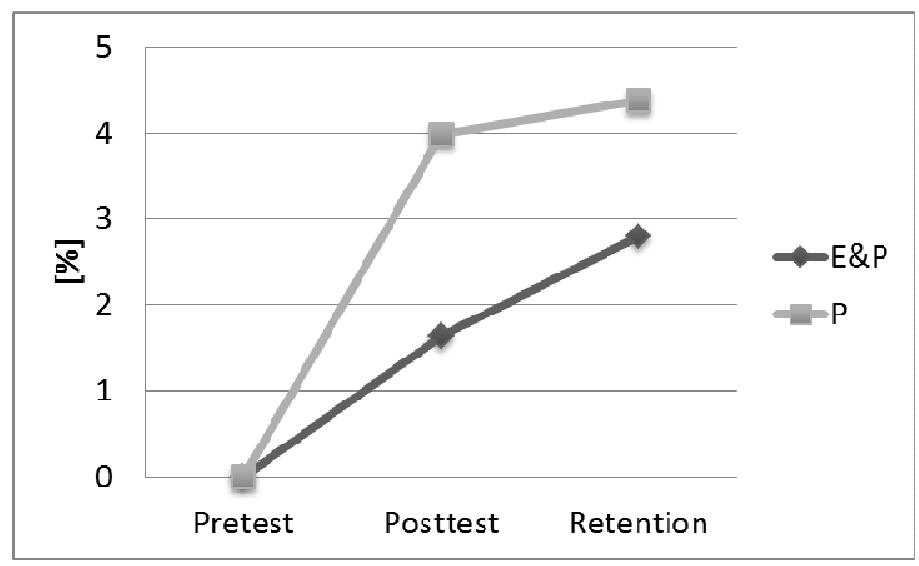

Figure 2. Relative improvement of judges' ratings

The ratings observed in the posttest were significantly higher than in the pretest $(4 \% ; \mathrm{p}<.012)$ and a further increase in ratings to $4.4 \%$ during the retention $(\mathrm{p}<.007)$ pointed to the improvement of the task performance. However, it was insignificant between posttest and retention measurements $(p=.788)$. All judges' ratings observed in the group with verbal information on errors and correctness (E\&P) improved insignificantly. The effect size for differences between groups ranged from 1.79 (posttest) to 1.41 (retention).

\section{Discussion}

The study aimed at explaining how two different strategies of providing feedback influence the process of learning complex movement tasks. A lot of authors highlight the fact that too much information may exert a negative effect on the outcome of learning due to limited abilities of a learner to process feedback.

It was assumed that giving information on the correctness of performing the task would be as efficient as providing feedback on errors and on how to correct them. Drawing on the obtained study results it may be stated that different strategies of giving verbal feedback to a learner bring about diverse effects. It was observed that the two groups demonstrated statistically significant improvements in scores both in the posttest and in the retention test. The subjects from group $\mathrm{P}$, who received feedback on the correctness of performing the task, achieved better results than the learners from group E\&P, who got information regarding errors and ways of correcting them (the effect size for the posttest was 1.79 and for the retention test it was 1.41). Both groups manifested an insignificant improvement in their scores in the retention test. These findings are not parallel with the data obtained by researchers testing the guidance hypothesis in complex movement skills. They claim that after ceasing to provide feedback to those who have been given the so-called $100 \%$ feedback, the results deteriorate in the retention test.

The results show that both groups improved their performance in the retention test. However, the subjects from group P, who received less feedback, achieved relatively better results than those from group E\&P, who were given more information.

It seems that the type of a task is a key factor determining the selection of a proper strategy of providing feedback on the quality and the outcome of a task performance. The obtained results correspond with the findings of Tzetzis and Votsis [16], who claim that in learning complex tasks positive feedback must combine information on errors committed while performing a task and ways of correcting them since the subjects from group E\&P, who received such information, improved their scores insignificantly ( $p>.05)$. The subjects from group $P$, who got information on the performance correctness only, obtained better results. It may indicate that the quantity of information and the frequency of providing a learner with it are the main factors determining the efficiency of learning.

One should agree with Laguna [3], who claims that the efficiency of learning complex movement tasks depends on their level of difficulty and specificity of feedback (task-related information), which is indirectly borne out by our findings.

Our research was limited by the fact that two learning strategies were applied to one complex movement task only. Future research ought to be conducted taking into consideration movement tasks of different complexity and different strategies of providing feedback.

\section{Conclusions}

1. At early stages of learning too much verbal information is not the basis for acquiring complex movement tasks and most often it hinders the process of learning.

2. Providing too much verbal feedback on errors and the correctness of a task performance turned out to be less efficient than giving only verbal information on the correctness of performing a vertical jump with pulling the knees to the chest and grabbing the shanks.

3. Understanding these types of variables may lead to getting to know the role of feedback and of the process of learning complex movement tasks better. 


\section{Sadowski et al.: VERBAL FEEDBACK IN LEARNING}

4. A challenge for future research is to find out if the results of our experiment may be applied in the process of learning other more complex movement tasks.

\section{Acknowledgements}

The research was accomplished within the framework of research project of Faculty of Physical Education and Sport in Biała Podlaska, the Josef Pilsudski University of Physical Education in Warsaw - DS.142 - financed by the Ministry of Science and Higher Education.

\section{Literature}

1. More, K.G. \& Franks I.M. (1996). Analysis and modification of verbal coaching behaviour: the usefulness of a data-driven intervention strategy. J. Sports Sci. 14, 523-543.

2. Hughes, M. \& Franks I.M. (1997). Notational analysis in sport. London: E \& FN Spon.

3. Laguna, P. (2008). Task complexity and sources of taskrelated information during the observational learning process. J. Sports Sci. 26, 1097-1113.

4. McCullagh, P. \& Little W.S. (1990). Demonstration and knowledge of results in motor skill acquisition. Percept. Mot. Skills 71, 735-742.

5. Silverman, S. (1994). Communication and motor skill learning: What we learn from research in the gymnasium. Quest 46, 345-355.

6. Franks, I.M. (1997). The use of feedback by coaches and players. In T. Reilly, J. Bangsbo \& M. Hughes (Eds.), Science and football III (pp. 267-278). London: E \& FN Spon.

7. Sanchez, X. \& Bampouras M.T. (2006). Augmented feedback over a short period of time: Does it improve netball goalshooting performance? Int. J. Sport Psychol. 37, 349-358.
8. Kernodle, M.W. \& Carlton L.G. (1992). Information feedback and the learning of multiple-degree-of-freedom activities. J. Motor Behav. 24, 187-196.

9. Bandura, A. (1997). Self-efficacy: The exercise of control. Am. J. Health Promo. 12, 8-12.

10. Scheeler, M.C. \& Lee D.L. (2002). Using technology to deliver immediate corrective feedback to preservice teachers. J. Behav. Educ. 1, 231-241.

11. Newell, K.M. \& Walter C. B. (1981). Kinematic and kinetic parameters as information feedback in motor skill acquisition. J. Hum. Mov. Stud. 7, 235-254.

12. Lee, M.A., Keh C.N. \& Magill A.R. (1993). Instructional effects of teacher feedback in physical education. J. Teach. Phys. Educ. 12, 228-243.

13. Landin, D. (1996). The role of verbal cues in skill learning. Quest 46, 299-313.

14. Kernodle, M.W., Johnson R. \& Arnold D.R. (2001). Verbal instruction for correcting errors versus such instructions plus videotape replay on learning the overhead throw. Percept. Mot. Skills 92, 1039-1051.

15. Scheeler, M.C., Ruhl K. \& McAfee J. (2004). Providing performance feedback to teachers: A review. Teach. Educ. Spec. Educ. 27(4), 396-407.

16. Tzetzis, G. \& Votsis E. (2006). Three feedback methods in acquisition and retention of badminton skills. Percept. Mot. Skills 102, 275-284.

17. Williams, A.M. \& Hodges J.N. (2005). Practice, instruction and skill acquisition in soccer: Challenging tradition. J. Sports Sci. 23(6), 637-650.

Submitted: December 7, 2011

Accepted: December 23, 2011 